\title{
ANALISIS KEBUTUHAN KOMPETENSI SDM BIDANG LOGISTIK DENGAN METODA ANALYTICAL HIERARCHY PROCESS
}

\author{
Putu Diva Ariesthana Sadri*, Putu Ayu Govika Krisna Dewi, Ni Luh Darmayanti \\ Manajemen Logistik, Politeknik Transportasi Darat Bali, Jl. Cempaka Putih, Desa Samsam, Kec.Kerambitan, \\ Kab. Tabanan - Bali, Indonesia 80582 \\ *diva@poltradabali.ac.id
}

\begin{abstract}
ABSTRAK
Perkembangan perekonomian suatu negara akan mendorong tingginya permintaan jasa logistik mengingat intensitas perpindahan barang sangat besar dalam pasar global. Penelitian bermaksud melakukan identifikasi kompetensi yang harus dimiliki oleh tenaga kerja perusahaan jasa logistik dalam rangka mewujudkan penguatan sistem logistik nasional. Penelitian diharapkan dapat memberikan gambaran kepada Politeknik Transportasi Darat Bali sebagai institusi yang baru dalam bidang pelatihan dan pendidikan logistik dalam mengkaji penetapan capaian pembelajaran lulusan agar peserta didik terserap secara maksimal di industri jasa logistik. Pengumpulan data primer penelitian menggunakan kuesioner yang disusun berdasarkan studi literatur. Kuesioner disebarkan secara langsung kepada stakeholder dan menggunakan google form/sheet. Metode pengolahan data menggunakan Analytical Hierarchy Process (AHP) dengan mengurutkan peringkat kompetensi yang dibutuhkan oleh calon pengguna lulusan Prodi Diploma III Manajemen Logistik Poltrada Bali. Berdasarkan analisa data hasil survey, Kompetensi yang paling penting dibutuhkan pada industry logistic adalah kemampuan berbahasa asing sedangkan tahapan terpenting dalam industry adalah tahapan perencanaan, dilanjutkan secara berturut-turut tahapan pelaksanaan, pengawasan dan pelaporan. Diharapkan nantinya dengan adanya penelitian ini terjadi sinkronisasi (link and match) antara penyedia dan pengguna lulusan. Sehingga tercipta lulusan yang siap pakai dan siap kerja di dunia usaha dan industri khususnya logistik.
\end{abstract}

Kata kunci: analytical hierarchy process method; kompetensi; sdm logistik

\section{COMPETENCY ANALYSIS OF HUMAN RESOURCES IN LOGISTICS WITH ANALYTICAL HIERARCHY PROCESS METHOD}

\begin{abstract}
The economic development of a country will encourage high demand for logistics services, related to large intensity of movement of goods in global market. The research aims to identify the competencies that must be possessed by logistic human resources in order to strengthen national logistics system. The research is expected to provide an overview for Politeknik Transportasi Darat Bali to determine and provide outcomes that maximally absorbed in logistics service industry. The collection of research data is using a questionnaire compiled based on a literature study. The questionnaire distributed directly to stakeholders and indirectly by google form / sheet. The data analysis method uses Analytical Hierarchy Process (AHP) by ranking the competency required by prospective users of the Diploma III Logistics Management in Politeknik Transportasi Darat Bali. Based on the data analysis, the most important competence needed in the logistics industry is an ability to speak foreign languages, while the most important stage in the industry is planning stage, followed by implementation, supervision and reporting stage. It is expected that there will be synchronization (link and match) between providers dan graduate users. In order to create graduates who are ready to work in logistics industry.
\end{abstract}

Keywords: analytical hierarchy process method; competency; logistic human resources

\section{PENDAHULUAN}

Laporan Logistics Performance Index (LPI) menyatakan bahwa perusahaan internasional menghadapi masalah terkait kekurangan tenaga kerja yang memenuhi persyaratan kompetensi operasional logistik (Arvis et al., 2016). Sebagian besar operasional logistik perusahaan 
internasional ditangani oleh perusahaan jasa logistik internasional. Kondisi tersebut mengharuskan tenaga kerja di perusahaan jasa logistik memiliki kompetensi yang dapat digunakan untuk menghadapi berbagai situasi dalam konteks rantai pasokan global.

Daya saing Indonesia berdasarkan Logistics Performance Index (LPI) secara agregat dari tahun 2012 sampai dengan 2018 menunjukkan bahwa Indonesia berada pada peringkat ke lima puluh satu (51). Indonesia kalah bersaing dengan negara Asia Tenggara lainnya seperti Singapura, Thailand, Malaysia dan Vietnam. Salah satu penyebabnya sumber daya manusia logistik nasional sampai saat ini masih kurang memadai disertai terbatasnya Lembaga Pendidikan dan Pelatihan di Bidang Logistik.

Politeknik Transportasi Darat (Poltrada) Bali merupakan salah satu institusi pemerintahan dibawah Kementerian Perhubungan yang baru mendirikan program studi dibidang logistik yaitu Diploma III Manajemen Logistik. Program studi Diploma III Poltrada Bali bertujuan menjadi lembaga yang profesional dalam menyelenggarakan pendidikan dan pelatihan dibidang logistik. Program studi D-III Manajemen Logistik juga diselenggarakan untuk menjawab tantangan penyediaan sistem pengangkutan dan aliran rantai pasok yang aman dan selamat.

Penelitian bermaksud melakukan identifikasi kompetensi yang harus dimiliki oleh tenaga kerja perusahaan jasa logistik dalam rangka mewujudkan penguatan dalam sistem logistik nasional serta mendorong terciptanya sumber daya manusia logistik yang andal dan memenuhi standar kebutuhan yang ditetapkan oleh perusahaan iasa logistik. Penelitian juga bertujuan menjawab permasalahan yang dikemukakan (Arvis et al., 2016) agar terdapat sinkronisasi antara kebutuhan kompetensi tenaga kerja bidang logistik dengan pelatihan atau pendidikan yang diberikan oleh akademisi. Penelitian diharapkan dapat memberikan gambaran kepada Politeknik Transportasi Darat Bali sebagai institusi yang baru dalam bidang pelatihan dan pendidikan logistik dalam mengkaji penetapan capaian pembelajaran lulusan agar peserta didik terserap secara maksimal di industri jasa logistik.

Kompetensi yang akan diidentifikasi adalah kompetensi tenaga kerja operator dalam perusahaan jasa logistik. Tenaga kerja operator dalam perusahaan jasa logistik terbagi dalam beberapa kegiatan yaitu shipping, staging, supply, packing dan receiving. Manajemen atas seperti Direktur dan Manager tidak disertakan dalam identifikasi mengingat posisi tersebut memerlukan tidak hanya kompetensi teknis namun juga terkait perencanaan yang strategis. Pertimbangan lain terkait fokus identifikasi kompetensi khusus operator, mengingat lulusan Diploma III Manajemen Logistik lebih memenuhi standar untuk bekerja pada posisi tersebut.

Keterampilan berasal dari kata terampil yang artinya cakap, mampu, dan cekatan. Keterampilan seseorang dipengaruhi oleh kemampuan dasar yang dimilikinya serta intensitas pelatihan telah diikutinya. Kemampuan dasar yang baik diikuti dengan pelatihan yang memadai akan membantu seseorang menghasikan sesuatu yang lebih bernilai dengan lebih cepat. Keterampilan logistik mencerminkan keterampilan profesional yang terkait dengan bidang logistik.

Lin dan Chang (2018) mengemukakan ada lima Keterampilan yang perlu dimiliki oleh operator logistik yaitu manajemen lalu lintas/ transportasi, layanan pelanggan, pergudangan, pengendalian persediaan dan penanganan material. Keterampilan logistik yang penting termasuk pengetahuan profesional logistik, peraturan bea cukai, kemampuan pembelian, manajemen pengiriman, perencanaan bahan baku, dan manajemen penyimpanan. Wu et al. (2013) menyarankan operator di bidang logistik seharusnya memiliki beberapa Keterampilan antara lain hukum, bea cukai, manajemen ekspor dan impor, manajemen transportasi, 
manajemen persediaan, pergudangan, pembelian dan pengadaan, peramalan kebutuhan, manajemen pelabuhan atau bandara dan sistem informasi logistik.

\section{METODE}

Data penelitian berupa populasi dan sampel merupakan data primer yang diperoleh dari kuesioner. Pemilihan sampel menggunakan metode purposive sampling, berdasarkan jumlah populasi yang berhasil dikumpulkan. Metode AHP memungkinkan untuk menggunakan sampel dalam jumlah kecil (sekitar 30 sampel). Purposive sampling menjadi dasar peneliti memilih perusahaan besar atau perusahaan logistic lokal yang memiliki pembagian tugas dan fungsi jelas bidang logistik/angkutan barang. Memlih responden dengan data latar belakang logistik atau ahli dalam bidang logistic. Penelitian memperoleh 103 responden yang menjadi populasi dan didapat sampel sebanyak 43 responden. Sampel dipilih berdasarkan kriteria diatas. Berdasarkan kuesioner yang diisi oleh 43 data responden diatas, peneliti selanjutnya melaksanakan uji validitas dan uji reliabilitas data. Tujuannya untuk memastikan bahwa data yang akan dianalisis sudah valid dan reliabel.

Metode pengolahan data menggunakan Analytical Hierarchy Process (AHP) dimana analisis tersebut akan mengurutkan peringkat kompetensi sesuai dengan tingkat kebutuhan oleh stakeholder calon pengguna lulusan Prodi Diploma III Manajemen Logistik Poltrada Bali. Di dalam AHP, penetapan prioritas kebijakan dilakukan dengan menangkap secara rasional persepsi orang, kemudian mengkonversi faktor-faktor yang intangible (yang tidak terukur) ke dalam aturan biasa, sehingga dapat dibandingkan. Adapun tahapan dalam analisa data sebagai berikut (Saaty, 2004):

1) Identifikasi sistem dengan mengidentifikasi permasalahan dan menentukan solusi. Identifikasi sistem dapat dilakukan dengan mempelajari referensi dan berdiskusi dengan para pakar yang memahami permasalahan, sehingga diperoleh konsep relevan dengan permasalahan;

2) Penyusunan struktur hirarki yang diawali dengan tujuan umum, dilanjutkan dengan sub tujuan, kriteria dan alternatif-alternatif pada tingkatan kriteria paling bawah;

3) Perbandingan berpasangan, menggambarkan pengaruh relatif setiap elemen terhadap masing-masing tujuan atau kriteria yang setingkat diatasnya. Teknik perbandingan berpasangan yang digunakan dalam AHP berdasarkan "Judgement" atau pendapat dari para responden yang dianggap sebagai "key person". Mereka dapat terdiri atas : 1. Pengambil keputusan; 2. Para Pakar; 3. Orang yang terlibat dan memahami permasalahan yang dihadapi;

4) Matriks pendapat individu

Tabel 1.

Formulasi Matriks Pendapat

\begin{tabular}{lllll}
\hline & $\mathrm{C} 1$ & $\mathrm{C} 2$ & $\ldots \ldots \ldots \ldots$ & $\mathrm{Cn}$ \\
\hline $\mathrm{C} 1$ & 1 & $\mathrm{a} 12$ & $\ldots \ldots \ldots \ldots$ & $\mathrm{A} 1 \mathrm{n}$ \\
\hline $\mathrm{C} 2$ & $1 / \mathrm{a} 12$ & 1 & $\ldots \ldots \ldots \ldots$ & $\mathrm{A} 2 \mathrm{n}$ \\
\hline$\ldots \ldots \ldots$ & $\ldots \ldots \ldots \ldots \ldots \ldots \ldots \ldots$ & $\ldots \ldots \ldots \ldots$ \\
\hline $\mathrm{Cn}$ & $1 / \mathrm{a} 1 \mathrm{n}$ & $\ldots \ldots \ldots \ldots \ldots \ldots \ldots$ & $\ldots \ldots \ldots \ldots$ & 1 \\
\hline
\end{tabular}

Dalam hal ini $\mathrm{C} 1, \mathrm{C} 2, \ldots . ., \mathrm{Cn}$ adalah set elemen pada satu tingkat dalam hirarki. Kualifikasi pendapat dari hasil perbandingan berpasangan membentuk matriks $\mathrm{n} \times \mathrm{n}$. Nilai aij merupakan nilai matriks pendapat hasil perbandingan yang mencerminkan nilai kepentingan $\mathrm{Ci}$ terhadap $\mathrm{Cj}$. 
5) Matriks pendapat gabungan, merupakan matriks baru yang elemen-elemenya berasal dari rata-rata geometri elemen pendapat individu yang nilai rasio inkonsistensinya memenuhi syarat;

6) Pengolahan horizontal, yaitu ; a. Perkalian baris; b. Perhitungan vector prioritas atau vector cirri (eigen vector); c. Perhitungan akar cirri (eigen value) maksimum, dan d. Perhitungan rasio inkonsistensi. Nilai pengukuran konsistensi diperlukan untuk menghitung konsistensi jawaban responden.

7) Pengolahan vertikal, digunakan untuk menyusun prioritas pengaruh setiap elemen pada tingkat hirarki keputusan tertentu terhadap sasaran utama;

8) Revisi pendapat, dilakukan bila nilai rasio konsistensi pendapat cukup tinggi $(>0.1)$. Beberapa ahli berpendapat jika jumlah revisi terlalu besar, sebaiknya responden tersebut dihilangkan. Jadi penggunaan revisi sangat terbatas mengingat akan terjadinya penyimpangan dari jumlah jawaban sebenarnya.

Menurut Suryadi dan Ramdhani (2002) dalam teori matriks diketahui bahwa kesalahan kecil pada koefisien akan menyebabkan penyimpangan kecil pula pada eigen value. Dengan mengkombinasikan apa yang telah diuraikan sebelumnya, jika diagonal utama dari matriks A bernilai satu dan jika A konsisten, maka penyimpangan kecil dari Cij akan tetap menunjukkan eigen value terbesar, nilainya akan mendekati $\mathrm{n}$ dan eigen value sisanya akan mendekati nol. Penyimpangan dari konsistensi dinyatakan dengan Indeks Konsistensi (Saaty, 2004) dengan persamaan sebagai berikut:

dimana: a maks : eigen value maksimum

$$
\mathrm{CI}=\mathrm{a} \text { maks }-\mathrm{n} / \mathrm{n}-1
$$

n : ukuran matriks

Perbandingan CI (Indeks Konsistensi) dan RI (Indeks Random) untuk suatu matriks didefinisikan sebagai rasio konsistensi (CR).

$$
\begin{aligned}
\text { dimana }: \text { CR }: \text { Ratio Konsistensi } \\
\text { CI }: \text { Indeks Konsistensi } \\
\text { RI }: \text { Indeks Random }
\end{aligned}
$$

$$
\mathrm{CR}=\mathrm{CI} / \mathrm{RI}
$$

\begin{tabular}{|c|c|c|c|c|c|c|c|c|}
\hline $\begin{array}{c}\text { Komponen Uji Validitas } \\
\text { \& Reliabilitas }\end{array}$ & 1 & 2 & 3 & 4 & $\begin{array}{l}\ldots \ldots \\
\text { Dst }\end{array}$ & 61 & 62 & 63 \\
\hline Rxy & 0,5949 & 0,7311 & 0,7814 & 0,7094 & & 0,6682 & 0,7429 & 0,7454 \\
\hline $\mathrm{t}$ hitung & 4,7394 & 6,8608 & 8,0168 & 6,4447 & & 5,7514 & 7,1069 & 7,1604 \\
\hline $\mathrm{t}$ tabel $(5 \%)$ & 1,6811 & & & & & & & \\
\hline Keterangan & valid & valid & valid & valid & & valid & valid & valid \\
\hline Jumlah Valid & 63 & & & & & & & \\
\hline Varians & 1,9391 & 3,2447 & 2,9635 & 4,3477 & & 2,6833 & 3,8992 & 2,5725 \\
\hline Jml Varian & 163,25 & & & & & & & \\
\hline Var Total & 5318,9 & & & & & & & \\
\hline Reliabilitas & 0,9849 & & & & & & & \\
\hline r hitung (Korelasi) & 0,5949 & 0,7310 & 0,78135 & 0,70939 & & 0,66823 & 0,74293 & 0,74542 \\
\hline & 3364 & 7045 & 9688 & 3899 & & 2339 & 4486 & 4654 \\
\hline $\mathrm{r}$ tabel $(5 \%)$ & 0,301 & 0,301 & 0,301 & 0,301 & & 0,301 & 0,301 & 0,301 \\
\hline Keterangan & valid & valid & valid & valid & & valid & valid & valid \\
\hline
\end{tabular}

\section{HASIL DAN PEMBAHASAN}

Tabel 2.

Hasil Uji Validitas dan Reliabilitas Sampel 
Tabel 3.

Hasil Uji AHP untuk Jenis Kompetensi

\begin{tabular}{|c|c|c|c|}
\hline Kompetensi & Jumlah (A) & Rata-Rata (B) & Hasil Bagi A dan B \\
\hline Bahasa Asing & 3,94 & 0,362 & 10,89 \\
\hline Teknologi Informasi & 2,72 & 0,226 & 12,05 \\
\hline $\begin{array}{l}\text { Peraturan Perundangan Nasional dan } \\
\text { Internasional }\end{array}$ & 1,73 & 0,155 & 11,17 \\
\hline Pergudangan dan Persediaan & 1,08 & 0,109 & 9,92 \\
\hline Manajemen Resiko & 0,64 & 0,076 & 8,52 \\
\hline Manajemen Transportasi & 0,36 & 0,049 & 7,34 \\
\hline \multirow[t]{4}{*}{ Penanganan Material } & 0,19 & 0,024 & 7,94 \\
\hline & & & 67,83 \\
\hline & & $\mathrm{n}$ & 7,00 \\
\hline & & Lamda Maks & 9,69 \\
\hline Consistency Index (CI) & (Lamda Maks - & & \\
\hline Consistency Index (CI) & 0,45 & & \\
\hline Consistency Ratio (CR) & Consistency Ind & ndom Index & \\
\hline Consistency Ratio (CR) & 0,34 & & \\
\hline
\end{tabular}

Tabel 4.

Urutan Peringkat Kompetensi Berdasarkan AHP Kompetensi $\%$

Bahasa Asing $36,17 \%$

Teknologi Informasi $22,60 \%$

Peraturan Perundangan Nasional dan Internasional $15,52 \%$

$10,86 \%$

Pergudangan dan Persediaan

Manajemen Resiko

$7,55 \%$

Manajemen Transportasi $4,86 \%$

Penanganan Material

$2,44 \%$

Peringkat

\begin{tabular}{l}
1 \\
\hline 2 \\
3 \\
\hline 4 \\
\hline 5 \\
\hline 6 \\
7
\end{tabular}

Tabel 5.

Hasil Uji AHP Untuk Proses Pekerjaan

\begin{tabular}{|c|c|c|c|c|c|}
\hline $\begin{array}{c}\text { Tahapan Logistik } \\
\text { (Bahasa Asing) }\end{array}$ & Perencanaan & Pelaksanaan & Pengawasan & Pelaporan & Jumlah \\
\hline & 0,545 & 0,262 & 0,14 & 0,053 & \\
\hline Perencanaan & 1 & 5,67 & 5,05 & 5,47 & \\
\hline Pelaksanaan & 0,176366843 & 1 & 5,7 & 5,67 & \\
\hline Pengawasan & 0,198019802 & 0,175438596 & 1 & 5,79 & \\
\hline Pelaporan & 0,182815356 & 0,176366843 & 0,172711572 & 1 & \\
\hline Perencanaan & 0,5450 & 1,4855 & 0,7070 & 0,2899 & 3,0275 \\
\hline Pelaksanaan & 0,0961 & 0,2620 & 0,7980 & 0,3005 & 1,4566 \\
\hline Pengawasan & 0,1079 & 0,0460 & 0,1400 & 0,3069 & 0,6008 \\
\hline Pelaporan & 0,0996 & 0,0462 & 0,0242 & 0,0530 & 0,2230 \\
\hline Tahapan Logistik & Jumlah & Rata-Rata & Hasil Bagi & & \\
\hline Perencanaan & 3,0275 & 0,545 & 5,5593 & & \\
\hline Pelaksanaan & 1,4566 & 0,262 & 5,5492 & & \\
\hline Pengawasan & 0,6008 & 0,140 & 4,2992 & & \\
\hline Pelaporan & 0,2230 & 0,053 & 4,1926 & & \\
\hline & \multicolumn{2}{|c|}{ Jumlah } & 19,6003 & & \\
\hline & \multicolumn{2}{|c|}{$\mathrm{n}$} & 4 & & \\
\hline & \multicolumn{2}{|c|}{ Lamda Maks } & 4,9001 & & \\
\hline Consistency Index & $=(\mathrm{CI})$ & \multicolumn{2}{|c|}{$($ Lamda Maks - n) / (n - 1) } & & \\
\hline Consistency Index & $=(\mathrm{CI})$ & \multicolumn{2}{|l|}{0,30} & & \\
\hline Consistency Ratio & $=(\mathrm{CR})$ & \multicolumn{2}{|c|}{ Consistency Index / Random Index } & & \\
\hline Consistency Ratio & $=(\mathrm{CR})$ & 0,33 & & & \\
\hline
\end{tabular}


Berdasarkan data hasil uji validitas dan reliabilitas sesuai tabel 1. dengan menggunakan margin error $5 \%(0,005)$ diperoleh hasil bahwa seluruh data yang dianalisis sudah dalam kategori valid dan memiliki tingkat reliabilitas tinggi sehingga data sampel layak digunakan dalam uji Analytical Hierarchy Process (AHP).

Untuk ke 6 jenis kompetensi lain, peneliti juga melaksanakan tahapan perhitungan yang sama, dan menghasilkan analisis data sebagai berikut:

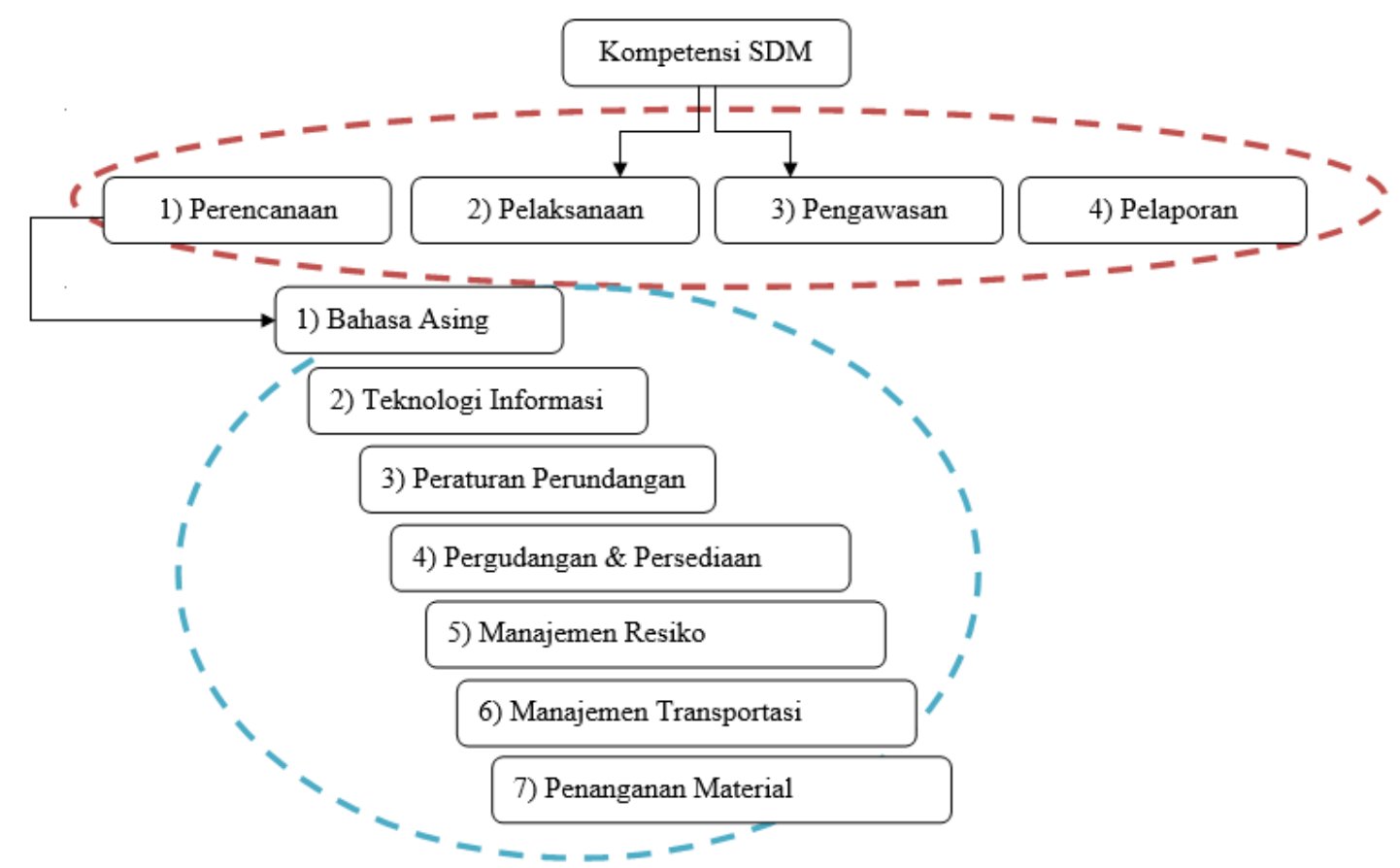

Gambar.1 Hasil Uji AHP untuk Peringkat Kompetensi dan Tahap Pekerjaan

Penguasaan bahasa asing menjadi kompetensi yang paling dibutuhkan oleh pelaku industri logistic. Temuan sejalan dengan penelitian Mayboroda et al. (2020) yang menemukan bahwa penguasaan bahasa asing atau bahasa internasional sangat penting dalam proses koordinasi berbagai pihak dan proses seperti eksekutif, bisnis, pembukuan, evaluasi, membangun relasi global, rekayasa perangkat lunak, inovasi, merancang mekanisme dan proses teknis. Bahasa internasional termasuk istilah atau terminologi dibidang logistik perlu dikuasai dan dipahami oleh seluruh pelaku industri termasuk operator tujuannya agar diperoleh pemahaman yang seragam antara pemberi dan penerima informasi (Mayboroda et al., 2020).

Pada era globalisasi, komunikasi melalui penguasaan bahasa asing menjadi kompetensi utama yang umumnya akan ditanyakan oleh perusahaan logistik saat proses rekrutmen. Hal tersebut dikarenakan perusahaan bidang logistik menyadari bahwa bisnis yang dijalankan melibatkan berbagai pihak dari luar negeri yang umumnya menggunakan bahasa internasional seperti bahasa Inggris. Untuk itu perusahaan akan mencari kandidat karyawan yang menguasai bahasa asing secara aktif. Penelitian menemukan bahwa penguasaan teknologi informasi menjadi kompetensi kedua yang penting dimiliki oleh lulusan program studi bidang logistik. Bukti empiris sejalan dengan penelitian Gunasekaran et al. (2016) yang mereviu beberapa literatur dalam sepuluh tahun terakhir terkait peran teknologi informasi pada industry logistik dan manajemen rantai pasokan. Gunasekaran et al. (2016) menemukan bahwa teknologi informasi menjadi sumber daya strategis untuk membangun keuntungan kompetitif. 
Pemahaman peraturan perundangan nasional dan internasional menjadi kompetensi ketiga yang penting dimiliki oleh tenaga kerja bidang logistik. Industri logistik melibatkan berbagai lembaga lokal, asing dan internasional baik pemerintah dan non permerintah. Keterlibatan antar lembaga telah diatur dalam perundangan seperti Peraturan Presiden (Perpres) No. 26 tahun 2016 tentang Cetak Biru Pengembangan Sistem Logistik Nasional (Sislognas). Pemahaman terhadap perundangan penting agar proses teknis logistik tidak terhambat dengan adanya pelanggaran perundangan yang dapat memberikan sanksi baik sanksi sanksi administrasi yang akan memperlambat waktu pengiriman barang atau sanksi berupa nominal uang.

Kompetensi selanjutnya yang dianggap penting dimiliki oleh tenaga kerja bidang logistik secara berurutan adalah penguasaan pergudangan dan persediaan, manajemen risiko, manajemen transportasi dan penanganan material. Berdasarkan urutan tersebut, instansi pendidikan perlu mengembangkan kurikulum yang sesuai dengan kebutuhan industri logistik terutama penguasaan bahasa asing. Pengajaran bahasa asing dapat menjadi mata kuliah yang diajarkan bukan hanya satu semester namun berkelanjutan pada semester berikutnya. Setelah mengetahui Kompetensi yang paling dibutuhkan tenaga kerja di bidang logistik, tim peneliti melanjutkan analisa mengenai proses pekerjaan pada bidang logistik yang terdiri dari 4 tahapan utama, yaitu tahapan perencanaan, tahapan pelaksanaan, tahapan pengawasan, dan tahapan pelaporan.

Kompetensi SDM bidang logistik di beberapa perusahaan logistik masih terdapat kesenjangan keahlian, keterampilan maupun kompetensi. Salah satu faktor yang menguatkan analisis tersebut adalah beberapa perusahaan logistik belum mau membuka diri mengenai kompetensi sumber daya manusia yang terdapat pada perusahaan masing-masing dikarenakan beberapa faktor seperti:

1) Ketakutan akan munculnya peraturan pemerintah terkait standar kompetensi sumber daya manusia yang bekerja di bidang logistic sehingga pengusaha harus menambah lagi tenaga kerja baru, atau mengganti tenaga kerja lama. Dimana dengan semakin tingginya pendidikan akan berbanding lurus dengan gaji yang harus ditanggung pengusaha.

2) Pengusaha diwajibkan meningkatkan kompetensi pegawai sehingga menimbulkan biaya tambahan.

3) Kondisi perusahaan kurang stabil dikarenakan pandemi Covid-19 sehingga cenderung tidak mau diberatkan oleh hal lain yang dianggap kurang menguntungkan.

Metode Analytical Hierarchy Process memerlukan interaksi dan konsistensi dari responden agar hasil kuesioner yang didapat benar-benar memberikan hasil yang optimal. Hal ini dipengaruhi oleh jumlah responden yang mengisi kuesioner, jumlah factor atau criteria serta kompetensi responden. Semakin banyak dan kompleks kuesioner juga memberikan pengaruh terhadap konsistensi responden saat memberikan penilaian kuesioner. Consistency Ratio pada penelitian ini memiliki nilai sedikit diatas ambang batas $(>0.1)$ hal ini disebabkan karena beberapa factor antara lain :

1) Factor atau criteria yang dibandingkan terlalu banyak.

2) Butir pertanyaan kuesioner terlalu banyak, sehingga menyita cukup banyak waktu pengisi kuesioner.

3) Waktu pengisian kuesioner dilaksanakan pada saat jam sibuk.

4) Pada saat pengisian kuesioner wajib ditemani oleh peneliti, sehingga apabila responden mengalami kebingungan dalam mengisi kuesioner, bisa segera ditindaklanjuti. 
Berdasarkan uji reliabilitas dan validitas yang dilakukan mendapatkan hasil yang sangat baik, terbukti semua data yang diperoleh valid dan reliable. Sehingga peneliti menyimpulkan hasil penelitian ini masih dapat diterima namun memerlukan penelitian lanjutan untuk menguatkan hasil penelitian agar lebih optimal.

\section{SIMPULAN}

Berdasarkan studi literatur yang dilakukan maka diperoleh tujuh jenis kompetensi SDM yang sangat diperlukan pada bidang industri logistik, dan empat tahapan pekerjaan bidang logistik. Penelitian menemukan dari tujuh kompetensi SDM yang dibutuhkan pekerja bidang logistik, kemampuan bahasa asing merupakan kompetensi yang penting dan harus dimiliki oleh pekerja bidang logistic. Berturut-turut diikuti oleh kompetensi bidang Teknologi Informasi, Peraturan Perundangan Nasional dan Internasional, Pergudangan dan Persediaan, Manajemen Resiko, Manajemen Transportasi, dan kompetensi terakhir adalah Penanganan Material. Tahapan pekerjaan terpenting di bidang logistik secara berturut turut adalah perencanaan, pelaksanaan, pengawasan, dan terakhir pelaporan. Kesenjangan kebutuhan kompetensi dikarenakan keberatan perusahaan akan penambahan beban terkait upaya peningkatan kompetensi SDM sehingga perlu diadakan kegiatan sosialisasi kepada pengusaha bidang logistik akan pentingnya pengaruh SDM yang berkompeten dalam meningkatkan kinerja perusahaan secara berkelanjutan.

\section{DAFTAR PUSTAKA}

Arvis, J.F, Saslavsky, D., Ojala, L., and Shepherd. B., 2016, Connecting to Compete, Trade Logistics in The Global Economy, The World Bank, Washington.

Anandhita dan Dwiardi, 2018, The Role of Information Technology in Supporting Logistics Process for Postal Operator in Digital Era, Jurnal Penelitian Pos dan Informatika, Vol. 8, No, 1, 77 -94.

Gunasekaran et al., 2016, Information technology for competitive advenateg within logistics dan supply chains: a review, 1-32.Hadi, S., Gunawan, I., \& Dalle, J., 2018, Statistika Inferensial, Rajawali Pers, Banjarmasin.

Hidayat, A., 2017, Desember 16, Rumus Slovin, Retrieved from Statistikian: https://www.statistikian.com/2017/12/hitung-rumus-slovin-sampel.html

Hugos, M.H., 2018, Essentials of Supply Chain Management, Fourth Edition, John Wiley \& Sons Ltd, United Kingdom.

Kovács, G. and Tatham, P., 2010. What is Special About A Humanitarian Logistician? A Survey of Logistic skills and performance, Supply Chain Forum: An International Journal, Vol. 11, No. 3, 32-41.

Lin, C. and Chang, C., 2018, Evaluating Skill Requirement for Logistics Operation Practitioners: Based on The Perceptions of Logistics Service Providers and Academics in Taiwan, The Asian Journal of Shipping and Logistics, Vol. 34, No. 04, 328-336.

Mangan, J. and Lalwani, C., 2016, Global Logistics and Supply Chain Management, Third Edition, John Wiley \& Sons Ltd, United Kingdom. 
Mayboroda et al., 2020, The Role of a Foreign Language in The Context of the International Standardization of Logistics Terminology, Journal Impact Factor, Vol. 11, No. 05, 1321-1331.

Mindtools, 2020, Maret 5, Paired Comparison Analysis. Retrieved from Mindtools: https://www.mindtools.com/pages/article/newTED_02.htm

Porter, M.E., 1985, Competitive Advantage: Creating and Sustaining Superior Performance: with a New Introduction, The Free Press, New York.

Santinorice, 2019, Oktober 14, Metode Survey, Retrieved from Santino Rice: https://santinorice.com/metode-survey/

Sitorus, B. dan Sitorus, T. I. H., 2017, Dukungan Transportasi Logistik dan Daya Saing Indonesia dalam Menghadapi Masyarakat Ekonomi Asean, Jurnal Manajemen Transportasi dan Logistik, Vol. 04, No. 02, 137-146.

Sugiyono, 2007, Statistika untuk Penelitian, Alfabeta, Bandung.

Sunarsih, N., 2017, Membangun Keunggulan Kompetitif Melalui Inovasi dan Kewirausahaan, Kewirausahaan dalam Multi Perspektif, 43 - 58.

Susanti, R., Setyosari, P., dan Abidin, Z., 2018, Persepsi Mahasiswa Teknologi Pendidikan Universitas Negeri Malang Tentang Pentingnya Keterampilan Dasar Mengajar Terhadap Kompetensi Lulusan Teknologi Pendidikan, Jurnal Kajian Teknologi Pendidikan, Vol. 1, No. 4, 263 - 271.

Wu, Y.C., Huang, S.K., Goh, M., and Hsieh Y.J., 2013, Global Logistics Management Curriculum: Perspective from Practitioners in Taiwan, An International Journal Supply Chain Management, Vol. 18, No. 4, 376 - 388. 
